12,03

\title{
Влияние температуры осаждения и отжига на люминесценцию германиевых нанокристаллов, сформированных в пленках $\mathrm{GeO}_{x}$ и многослойных структурах $\mathrm{Ge} / \mathrm{SiO}_{2}$
}

\author{
() Д.А. Грачев, А.В. Ершов, И.А. Карабанова, А.В. Пирогов, А.В. Нежданов, А.И. Машин, Д.А. Павлов
}

Нижегородский государственный университет им. Н.И. Лобачевского,

Нижний Новгород, Россия

E-mail: grachov@phys.unn.ru

(Поступила в Редакцию 14 марта 2016 г.)

\begin{abstract}
Методом физического осаждения в вакууме получены содержащие нанокристаллы германия пленки $\mathrm{GeO}_{x}$ и многослойные нанопериодические структуры $\mathrm{Ge} / \mathrm{SiO}_{2}$, управление свойствами которых осуществлялось путем варьирования температуры осаждения $\left(35-590^{\circ} \mathrm{C}\right)$ и отжига $\left(400-1000^{\circ} \mathrm{C}\right)$. Проведено сравнительное исследование оптических и структурных характеристик наносистем методами комбинационного рассеяния, ИК-спектроскопии, фотолюминесценции и электронной микроскопии, показавшими качественное подобие наносистем. Установлено, что отжиг при $600-800^{\circ} \mathrm{C}$ приводит к образованию нанокристаллов германия с высокой плотностью $\left(\sim 10^{12} \mathrm{~cm}^{-2}\right)$, в то время как в неотожженных материалах их плотность составляет $\sim 10^{10} \mathrm{~cm}^{-2}$. Средний размер нанокристаллов $5 \pm 2 \mathrm{~nm}$. Для обеих систем обнаружены три полосы люминесценции: при $1.2,1.5-1.7$ и $1.7-2.0 \mathrm{eV}$, происхождение которых связано с нанокристаллами $\mathrm{Ge}$, кислородно-дефицитными центрами в $\mathrm{GeO}_{x}$ и дефектами границы $\mathrm{Ge}$ /диэлектрик соответственно.
\end{abstract}

Работа выполнена при частичной поддержке РФФИ (гранты № 14-02-00119 и 15-02-05086).

DOI: 10.21883/FTT.2017.05.44388.091

\section{1. Введение}

В настоящее время практически достигнут предел быстродействия приборов микроэлектроники за счет уменьшения их размеров. В связи с этим наблюдается постепенный переход к интегральной оптоэлектронике, когда в едином технологическом цикле наряду с зарядовыми элементами на чипе формируются оптические. На пути такого развития стоит проблема низкой излучательной способности кремния и германия - базовых материалов электроники. Однако было показано, что наноразмерные кристаллические включения кремния в широкозонной диэлектрической матрице проявляют интенсивную люминесценцию при комнатной температуре в видимом и ближнем ИК-диапазонах [1]. Благодаря открытию данного эффекта композитные материалы на основе кремния остаются в ряду основных для интегральной электроники ближайшего будущего.

Материалам, содержащим нанокристаллы (НК) германия, уделено меньшее внимание, чем системам с НК кремния, хотя они обладают некоторыми важными достоинствами. Так, процесс формирования HK Ge реализуется при более низких температурах [2], что расширяет возможности зонной инженерии. Германий обладает низкой реакционной способностью, это повышает стабильность полученных наноструктур. Различие в зонных структурах кремния и германия делает исследование систем с HK Ge в диэлектрической матрице фундаментально важным для более углубленного понимания квантово-размерных эффектов в квантовых точках из непрямозонных материалов в целом.
До сих пор нет устоявшегося мнения о механизмах люминесценции, споры вызывает и диапазон свечения $\mathrm{HK}$ Ge. B литературе обсуждается набор полос в области $1-3 \mathrm{eV}$. Высокоэнергетические полосы $(\geq 2 \mathrm{eV})$ обладают большей интенсивностью, чем низкоэнергетические, поэтому первые работы были посвящены именно полосе около $3.1 \mathrm{eV}$ [3]. Впоследствии внимание авторов было сконцентрировано на полосе с максимумом $\sim 2.0 \mathrm{eV}[4]$. В обоих случаях связь данных полос излучения с HK $\mathrm{Ge}$ не была однозначно подтверждена экспериментально. Дальнейший более детальный анализ показал, что полосы при $2-3 \mathrm{eV}$ преимущественно являются результатом свечения дефектов [5-7]. В работах $[8,9]$ было продемонстрировано управление энергетическим положением максимума люминесценции системы $\mathrm{HK} \mathrm{SiGe}_{x}$ за счет изменения состава и размера нанокристаллов. Плавный переход от кремниевых наночастиц, спектр люминесценции которых достаточно хорошо изучен (см., например, [1]), к кремний-германиевым позволил утверждать, что „собственный“ спектр люминесценции НК Ge лежит в области $1.1-1.3 \mathrm{eV}$ [8,9]. До сих пор, однако, появляются публикации, подвергающие сомнению эти результаты. Цель настоящей работы заключается в попытке получения композитных структур с НК Ge в диэлектрике и анализа полос люминесценции в видимом диапазоне.

\section{2. Материалы и методика эксперимента}

Аморфные тонкие пленки $\mathrm{GeO}_{x}$ и многослойные нанопериодические структуры $a-\mathrm{Ge} / \mathrm{SiO}_{2}$ - два различных 
по составу типа структур — осаждались на подложки кремния и германия методом физического осаждения испарением в вакууме. Для получения пленок $\mathrm{GeO}_{x}$ испаряемым материалом служил монооксид германия $\mathrm{GeO}$ (II) марки хч. Многослойные наноструктуры получались поочередным испарением монокристаллического германия марки ГЭС-1 и плавленого кварца С5-1 электронным лучом из раздельных источников. Получение осуществлялось на комбинированной вакуумной установке 2G11G2-ElBeam-OQ-03 (Torr Int), оснащенной системой безмасляной откачки. Для контроля толщины пленок и структур использовалась система кварцего контроля. Давление остаточной атмосферы перед напылением не превышало $2 \cdot 10^{-6}$ Torr. В случае многослойных систем первым на подложку $\left(200^{\circ} \mathrm{C}\right)$ наносился германиевый слой, затем слой диоксида кремния, следующим наносился германиевый и т.д. Покровным был слой $\mathrm{SiO}_{2}$. Общее число слоев равно 19. Различные серии структур $a-\mathrm{Ge} / \mathrm{SiO}_{2}$ имели одинаковую толщину слоев $\mathrm{SiO}_{2}(4 \mathrm{~nm})$, в то время как толщина $a-\mathrm{Ge}$ варьировалась от 2 до $7 \mathrm{~nm}$. Отдельные пленки $\mathrm{GeO}_{x}$ толщиной $390 \mathrm{~nm}$ были получены при различных температурах подложки в диапазоне $35-590^{\circ} \mathrm{C}$.

После напыления образцы были разделены на чипы, которые отдельно отжигались в атмосфере азота при температуре $400-1000^{\circ} \mathrm{C}$ в горизонтальной трубчатой печи. Время отжига многослойных структур составляло $60 \mathrm{~min}$, а для пленок $\mathrm{GeO}_{x}-30 \mathrm{~min}$.

Измерение спектров комбинационного рассеяния света (КРС) в диапазоне $400-600 \mathrm{~cm}^{-1}$ проводилось с помощью сканирующего конфокального спектрометра зондовой нанолаборатории NTEGRA Spectra (NT-MDT) c использованием твердотельного лазера с длиной волны $474 \mathrm{~nm}$ и мощностью несфокусированного луча $\sim 1 \mathrm{~mW}$. Спектры ИК-пропускания измерялись при комнатной температуре на спектрометре Varian 4100 Excalibur co спектральным разрешением $2 \mathrm{~cm}^{-1}$ по методике многократного накопления сигнала в диапазоне $400-1400 \mathrm{~cm}^{-1}$.

Микроструктура образцов была установлена на просвечивающем электронном микроскопе высокого разрешения (ВРПЭМ) JЕМ-2100F. Характерные исследуемые площади составляли $50 \times 50 \mathrm{~nm}$. Для препарирования образцов использовалась модифицированная методика Gatan [10].

Спектры фотолюминесценции (ФЛ) измерялись при комнатной температуре в диапазоне длин волн 580-1100 nm на установке Nanometrics RPM PL Wafer Mapping System с использованием Nd : YAG-лазера мощностью $29.5 \mathrm{~mW}$ на длине волны $532 \mathrm{~nm}$. Для детектирования сигнала ФЛ использовалась матрица CCD512-TE с фильтром 570LP.

\section{3. Результаты}

На рис. 1 представлена карта ФЛ отожженных многослойных нанопериодических структур $\mathrm{Ge} / \mathrm{SiO}_{2}$

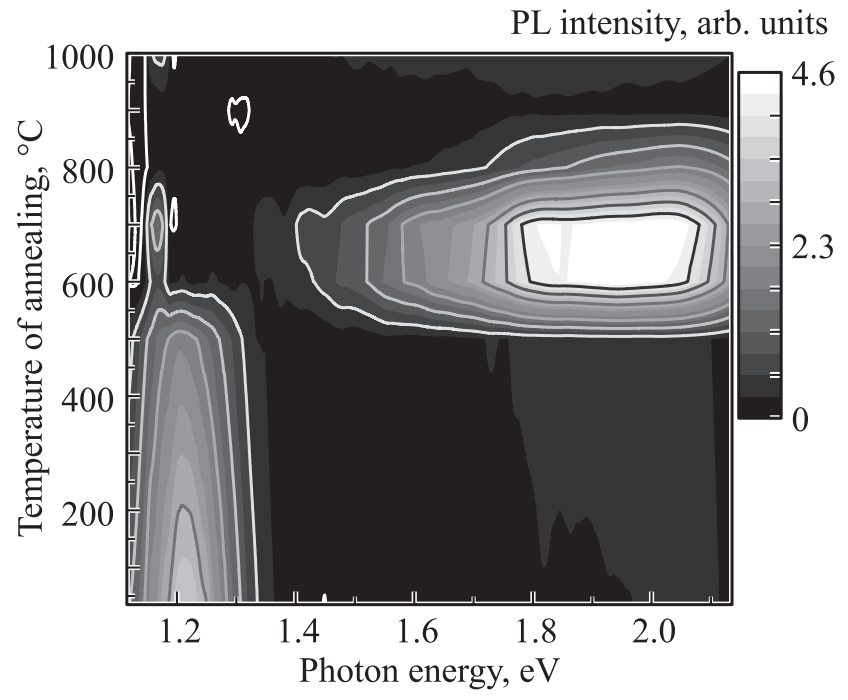

Рис. 1. Карта фотолюминесценции серии многослойных нанопериодических структур $\mathrm{Ge} / \mathrm{SiO}_{2}(4 \mathrm{~nm} / 4 \mathrm{~nm})$ в зависимости от температуры отжига.

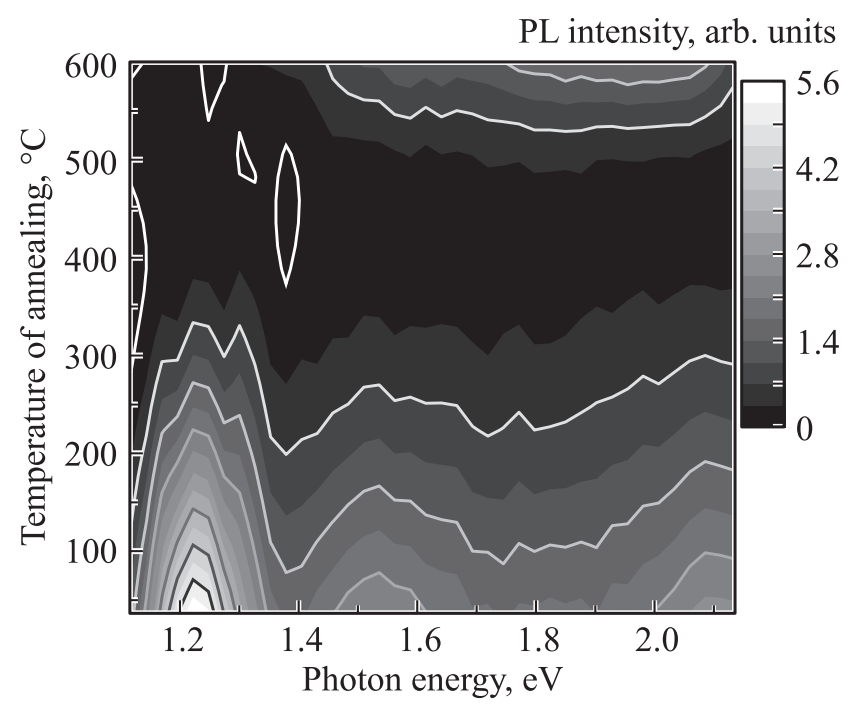

Рис. 2. Карта фотолюминесценции серии пленок $\mathrm{GeO}_{x}$, осажденных при $130^{\circ} \mathrm{C}$, в зависимости от температуры отжига.

(4 nm/ 4 nm). Белым цветом здесь обозначены наиболее интенсивные области свечения, снижение интенсивности отражено серым оттенком, а темно-серый цвет, переходящий в черный, соответствует люминесценции на уровне шума. В спектрах можно выделить две основные полосы, соответствующие разным температурам отжига. Так, в структурах, отожженных до $500^{\circ} \mathrm{C}$, выделяется полоса при $1.2 \mathrm{eV}$, связываемая в $[9,11,12]$ с излучением нанокристаллов германия. Для температур $600-800^{\circ} \mathrm{C}$ наблюдается широкая и интенсивная полоса в области $1.7-2.0 \mathrm{eV}$, что в работах $[5,13-15]$ объясняется люминесценцией поверхностных дефектов на границе НК $\mathrm{Ge}-\mathrm{SiO}_{2}$. 


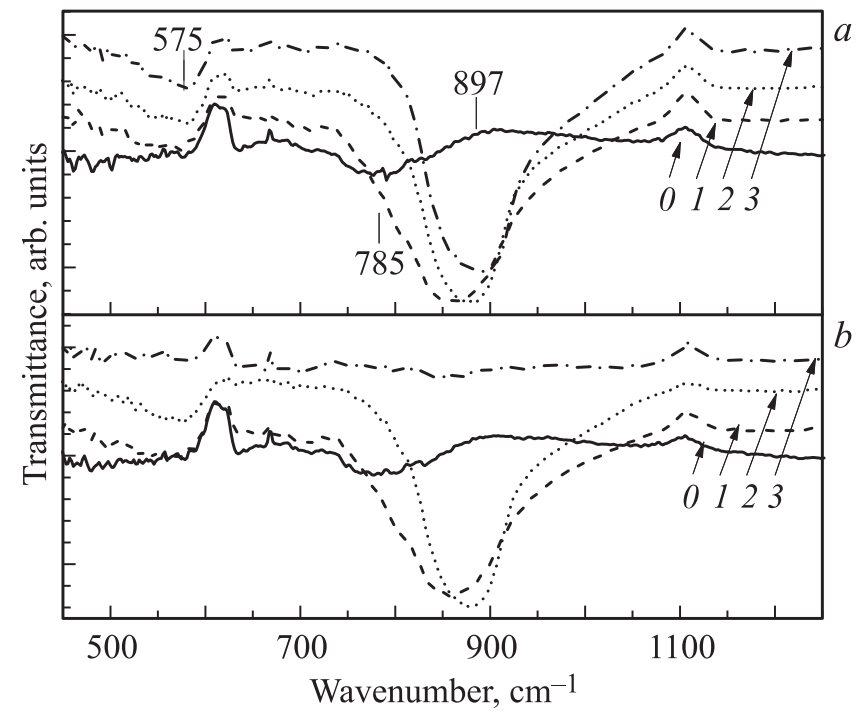

Рис. 3. Спектры ИК-пропускания пленок $\mathrm{GeO}_{x}$, осажденных при температурах подложки $130(a)$ и $220^{\circ} \mathrm{C}(b)$, до $(0)$ и после отжига при температурах 400 (1), 500 (2) и $600^{\circ} \mathrm{C}(3)$.

На рис. 2 показана карта ФЛ для пленок $\mathrm{GeO}_{x}$, температура подложки которых при осаждении составляла $130^{\circ} \mathrm{C}$. Несмотря на структурные отличия от многослойных структур $\mathrm{Ge} / \mathrm{SiO}_{2}$ и разницу в химическом составе, пленки $\mathrm{GeO}_{x}$ в зависимости от температуры отжига демонстрируют качественно подобную картину ФЛ. И здесь присутствуют две интенсивные полосы люминесценции: 1.2 и $1.6-2.0 \mathrm{eV}$. Первая из них, постепенно слабея при повышении температуры отжига, исчезает при достижении $300^{\circ} \mathrm{C}$, что немного меньше, чем для многослойных структур. Температура появления второй полосы также близка к случаю $\mathrm{Ge} / \mathrm{SiO}_{2}$ и составляет $500-600^{\circ} \mathrm{C}$.

На рис. $3, a, b$ представлены ИК-спектры пленок, полученных при $130^{\circ} \mathrm{C}$ (люминесценция приведена на рис. 2) и при $220^{\circ} \mathrm{C}$ соответственно. В спектрах видны две основные полосы поглощения колебаний $\mathrm{Ge}-\mathrm{O}$ : полоса колебаний, известных как колебания растяжения, в области $550-600 \mathrm{~cm}^{-1}$ и более ярко выраженная полоса колебаний изгиба при $750-900 \mathrm{~cm}^{-1}[7,11,14]$. В обоих случаях имеет место смещение максимума поглощения в область больших энергий и усиление поглощения, свидетельствующие о фазово-структурной модификации при термообработке. Отметим, что отжиг при $600^{\circ} \mathrm{C}$ приводит к исчезновению указанных полос поглощения для случая пленок $\mathrm{GeO}_{x}$, полученных при $220^{\circ} \mathrm{C}$ (кривая 3 на рис. $3, b)$.

Рис. 4 представляет поведение ИК-полосы изгибных колебаний $\mathrm{Ge}-\mathrm{O}\left(750-900 \mathrm{~cm}^{-1}\right)$ в пленках $\mathrm{GeO}_{x}$ в зависимости как от температуры подложки, так и от температуры отжига. Обратим внимание на то, что температура подложки слабо влияет на положение полосы ИК-поглощения: изолинии почти параллельны оси абсцисс, тогда как при повышении во всей области температуры отжига пик поглощения монотонно смещается от 780 до $890 \mathrm{~cm}^{-1}$, что свидетельствует о трансформации связей $\mathrm{Ge}-\mathrm{O}$. Максимум интенсивности полос поглощения приходится на температуру отжига $500-600^{\circ} \mathrm{C}$.

Влияние температуры подложки значительно лучше прослеживается на люминесцентных спектрах пленок $\mathrm{GeO}_{x}$. На рис. 5 представлена карта ФЛ в зависимости от температуры подложки для пленок без отжига. На ней отчетливо различимы две полосы люминесценции: 1.2 и $1.5-1.7 \mathrm{eV}$. Полоса $1.2 \mathrm{eV}$, также видимая на рис. 2 для области низких температур отжига, обладает максимальной интенсивностью для пленок, полученных при $220^{\circ} \mathrm{C}$. Дальнейший рост температуры подложки приводит к гашению люминесценции и появлению вто-

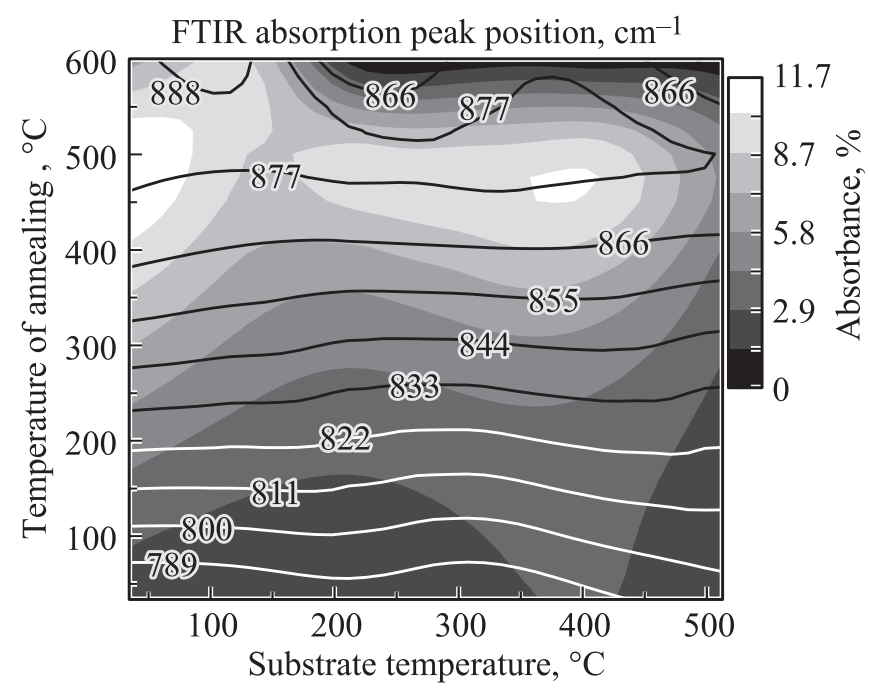

Рис. 4. Карта положения и интенсивности ИК-полосы поглощения колебаний изгиба $\mathrm{Ge}-\mathrm{O}$ в зависимости от температуры подложки и отжига. Положение показано изолинией, интенсивность - тоном.

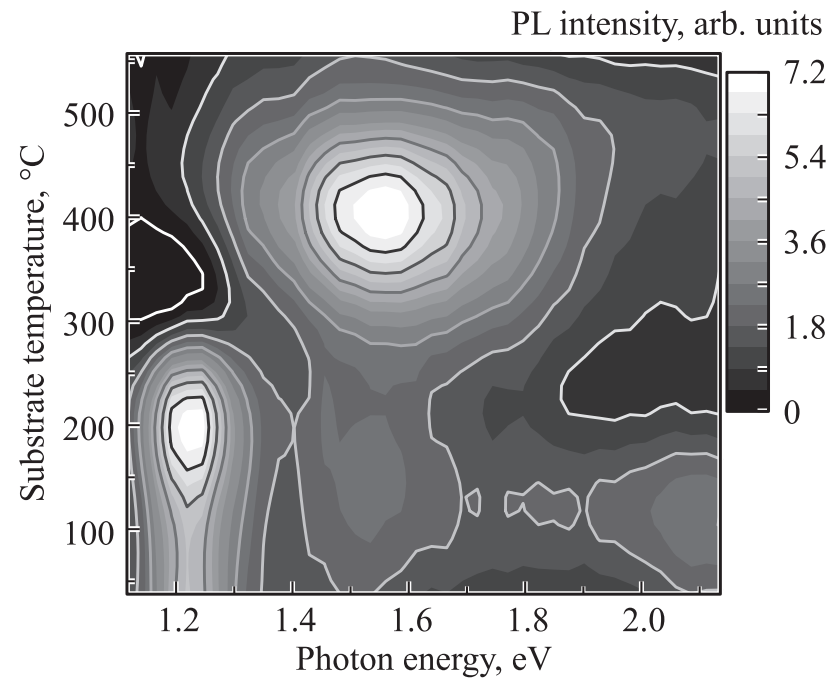

Рис. 5. Карта фотолюминесценции неотожженных пленок $\mathrm{GeO}_{x}$, различающихся температурой подложки. 
рой полосы $1.5-1.7 \mathrm{eV}$. Авторы [7,11] связывают ее происхождение с оптическими переходами $T_{\Pi}^{\prime} \rightarrow \mathrm{S}_{0}$ центров окраски $(780 \mathrm{~nm})$ в $\mathrm{GeO}$. В нашем случае максимум интенсивности этого свечения соответствует температуре подложки, равной $400^{\circ} \mathrm{C}$. Примечательно, что такое поведение полосы ФЛ при температуре подложки $400{ }^{\circ} \mathrm{C}$ коррелирует с повышением интенсивности поглощения изгибных колебаний $\mathrm{Ge}-\mathrm{O}$, как это следует из рис. 4.

Влияние температуры подложки на фазовый состав было изучено также методом КРС (рис. 6). Форма спектров пленок $\mathrm{GeO}_{x}$ не зависит от температуры подложки: во всех случаях наблюдается широкий пик рассеяния при $275 \mathrm{~cm}^{-1}$, характерный для аморфной фазы германия $[11,16]$. Интенсивность рассеяния, напро-

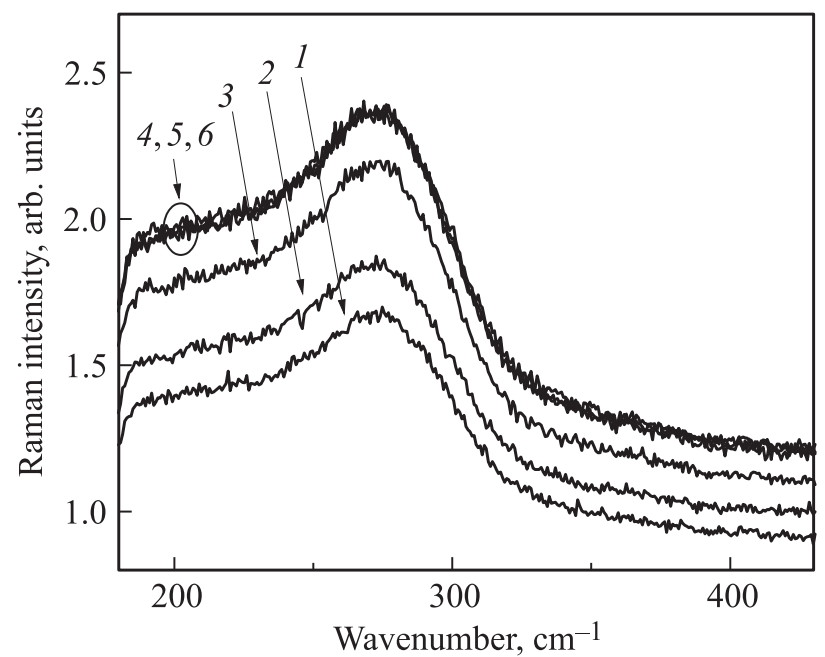

Pис. 6. Спектры комбинационного рассеяния света неотожженных пленок $\mathrm{GeO}_{x}$, различающихся температурой подложки. Кривые соответствуют следующим температурам осаждения: 35 (1), 130 (2), 220 (3), 300 (4), 410 (5), 510 $\mathrm{C}$ (6).
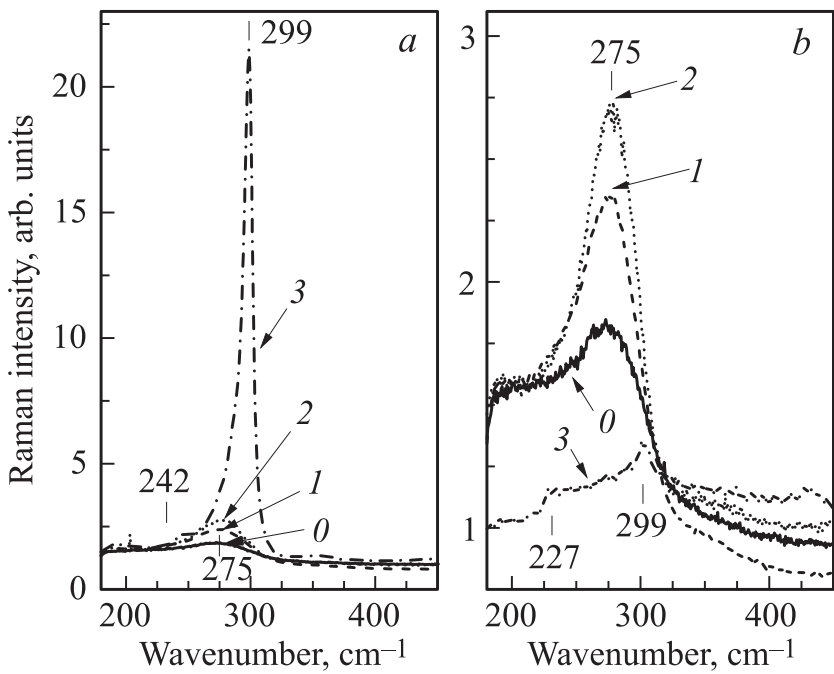

Pис. 7. Спектры комбинационного рассеяния света пленок $\mathrm{GeO}_{x}$, осажденных при температурах $130(a)$ и $220^{\circ} \mathrm{C}(b)$, до $(0)$ и после отжига при температурах 400 (1), 500 (2) и $600^{\circ} \mathrm{C}(3)$.

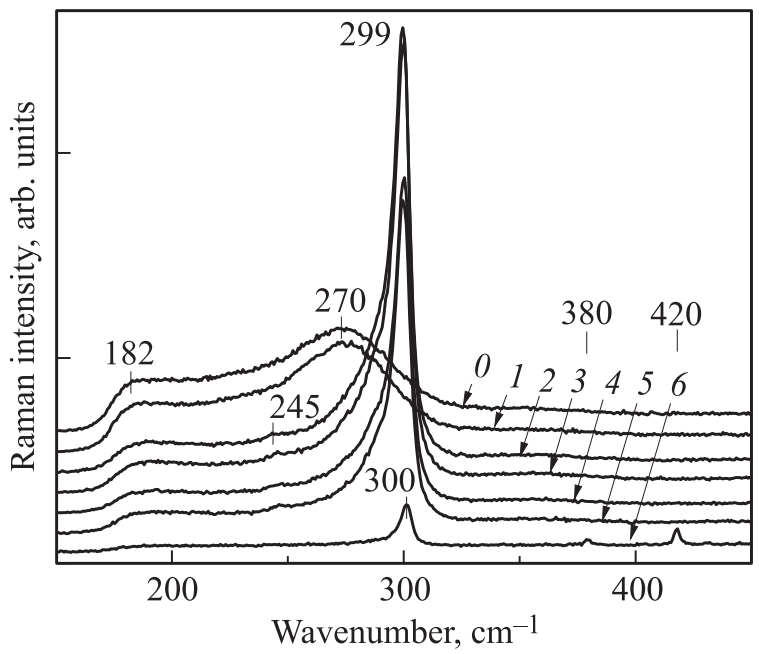

Рис. 8. Влияние температуры отжига на спектры комбинационного рассеяния света многослойной нанопериодической структуры $\mathrm{Ge} / \mathrm{SiO}_{2}(7 \mathrm{~nm} / 4 \mathrm{~nm})$. Кривая $O-$ до отжига, кривые $1-6$ - образцы, отожженные в диапазоне температур $500-1000^{\circ} \mathrm{C}$ с шагом $100^{\circ} \mathrm{C}$.

тив, растет при повышении температуры формирования от 35 до $300^{\circ} \mathrm{C}$ и не изменяется в диапазоне температур подложки $300-510^{\circ} \mathrm{C}$. Вновь обращаясь к карте ФЛ (рис. 5), видим, что как раз в области температур $300-500^{\circ} \mathrm{C}$ имеет место полоса ФЛ $\sim 1.6 \mathrm{eV}$.

Спектры КРС пленок $\mathrm{GeO}_{x}$ в зависимости от температуры отжига представлены на рис. 7, где аналогично данным по ИК-пропусканию (рис. 3) спектры приведены для двух температур подложки: 130 и $220^{\circ} \mathrm{C}$. Видно, что в обоих случаях интенсивность полосы рассеяния света аморфного германия $\left(275 \mathrm{~cm}^{-1}\right.$, кривые $\left.0-2\right)$ находится в прямой зависимости от температуры отжига. Для пленки, осажденной при $130^{\circ} \mathrm{C}$, отжиг при $600^{\circ} \mathrm{C}$ (рис. 7,a, кривая 3) приводит к появлению острого интенсивного пика с волновым числом $299 \mathrm{~cm}^{-1}$, свидетельствующего, согласно $[11,16]$, о наличии кристаллической фазы германия. Для более высоких температур осаждения $\mathrm{GeO}_{x}$ интенсивный пик при $299 \mathrm{~cm}^{-1}$ не наблюдался. Следует обратить внимание на то, что в этом случае в ИК-спектре пропадали полосы поглощения связей $\mathrm{Ge}-\mathrm{O}$ (рис. $3, b$ ).

Вернемся к рассмотрению многослойных наноструктур. Согласно данным КРС (рис. 8), отжиг при температуре $600^{\circ} \mathrm{C}$ образца $\mathrm{Ge} / \mathrm{SiO}_{2}$ с периодом $7 \mathrm{~nm} / 4 \mathrm{~nm}$, как и в случае пленок $\mathrm{GeO}_{x}$, приводит к кристаллизации германия. Отжиг же при температуре $800^{\circ} \mathrm{C}$ приводит к трансформации пика рассеяния от кристаллического германия $\left(299 \mathrm{~cm}^{-1}\right)$ : он значительно уменьшается по интенсивности и уширяется. При температуре отжига $1000^{\circ} \mathrm{C}$ пик КРС почти полностью исчезает, при этом появляются два слабых экстремума при 380 и $420 \mathrm{~cm}^{-1}$.

На рис. 9 представлены микроскопические снимки структуры $\mathrm{Ge} / \mathrm{SiO}_{2}$ со слоями толщиной $4 \mathrm{~nm}$ каждый. 

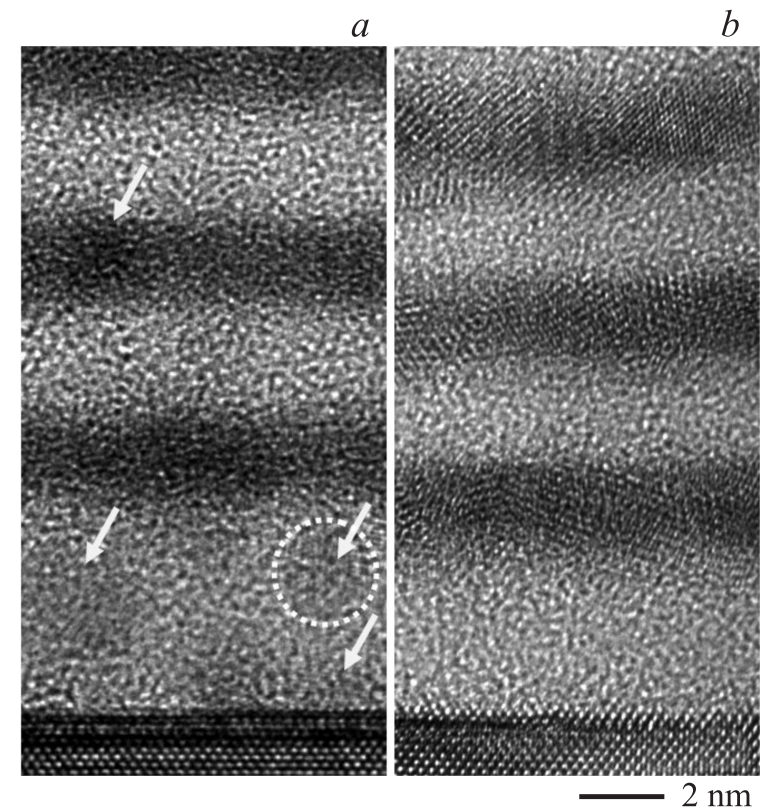

Рис. 9. ВРПЭМ-изображения поперечного среза нанопериодической структуры $\mathrm{Ge} / \mathrm{SiO}_{2}(4 \mathrm{~nm} / 4 \mathrm{~nm})$ до $(a)$ и после отжига при $800^{\circ} \mathrm{C}(b)$.

Видно, что до отжига (рис. 9, $a$ ) многослойная структура состоит из аморфных германия и диоксида кремния (темно-серые и светло-серые области соответственно). Фрагментарно (на поперечном срезе) в слоях диоксида кремния встречаются темно-серые кристаллические образования (отмечены стрелками). Определение межплоскостных расстояний и сравнение их с литературными значениями $[17,18]$ показали, что указанные редко расположенные кристаллические образования с видимой поверхностной плотностью $\sim 10^{10} \mathrm{~cm}^{-2}-$ нанокристаллы германия. Их средний размер в структурах до отжига составил $5 \pm 2 \mathrm{~nm}$. После отжига при $800^{\circ} \mathrm{C}$ структур $\mathrm{Ge} / \mathrm{SiO}_{2}$ на ВРПЭМ-снимке (рис. 9, $b$ ) не было обнаружено изолированных нановключений, в то время как на месте исходных аморфных слоев германия формируются массивные скопления плотно расположенных германиевых нанокристаллов (плотность $\sim 10^{12} \mathrm{~cm}^{-2}$ ) с размерами $\sim 5 \mathrm{~nm}$. Интересно, что в целом периодичность структуры после отжига сохраняется, но толщина самих слоев несколько (на $\sim 2 \mathrm{~nm}$ ) уменьшается.

\section{4. Обсуждение результатов}

Обсуждение результатов начнем с микроструктуры многослойных образцов $\mathrm{Ge} / \mathrm{SiO}_{2}$, для которых была выполнена электронная микроскопия высокого разрешения. Как до, так и после отжига в структурах содержатся нанокристаллы германия, но их порядок, расположение и поверхностная плотность различаются.

До отжига поверхностная плотность на ВРПЭМ-изображении сферических по форме кристаллических на- ночастиц ненапряженного германия настолько мала (рис. 9,a), что их можно считать изолированными.

После отжига при температуре $800^{\circ} \mathrm{C}$ наблюдаются крупные массивы - конгломераты близкорасположенных, подобных по размеру и сложных по форме германиевых нанокристаллов (рис. 9, $b$ ). Наблюдаемая по ВРПЭМ-снимкам кристаллизация германия под действием отжига при температурах 600-900 $\mathrm{C}$ подтверждается и данными КРС (рис. 8, кривые 2-5): все спектры имеют острый характерный пик при $\sim 300 \mathrm{~cm}^{-1}[11,16]$. По-видимому, отжиг при максимальной температуpe $\left(1000^{\circ} \mathrm{C}\right)$ приводил к активной диффузии германия, растворению германиевых кристаллических частиц и образованию кремний-германиевых сплавов, о чем свидетельствует пик КРС в области $420 \mathrm{~cm}^{-1}$ [19]. Заметим, что по результатам рамановской спектроскопии неотожженные многослойные образцы содержат лишь аморфную фазу германия (рис. 8, кривая 0): широкий пик при $270 \mathrm{~cm}^{-1}[11,16]$, что противоречит данным электронной микроскопии. Это расхождение может быть объяснено малой поверхностной плотностью $\mathrm{HK} \mathrm{Ge}$, т. е. объемом кристаллической фазы германия, недостаточным для обнаружения КРС-спектрографом.

Интересно проследить корреляцию $[5,13,14]$ поведения между интенсивностью ФЛ-полосы $1.7-2.0 \mathrm{eV}$ (рис. 1) и интенсивностью пика рамановского рассеяния от фазы кристаллического германия при $300 \mathrm{~cm}^{-1}$ (рис. 8). Так, ступенчатое уменьшение интенсивности пика рассеяния при температуре отжига образцов свыше $800^{\circ} \mathrm{C}$ (рис. 8 , кривые 3 и 4) происходит одновременно с исчезновением высокоэнергетической полосы фотолюминесценции (рис. 1), отмеченной как дефектная в работе [20]. Полагая подобную интерпретацию происхождения этой полосы ФЛ в нашем случае, можно считать, что под действием высоких температур происходит отжиг дефектов, участвующих в процессе люминесценции, а также частичное растворение германиевых кристаллических нанообразований.

Аналогичные спектры КРС и ФЛ демонстрируют пленки $\mathrm{GeO}_{x}$ : острый рамановский пик при $299 \mathrm{~cm}^{-1}$ (рис. 7, $a$, кривая 3) наблюдается совместно с полосой люминесценции в области $2.0 \mathrm{eV}$ (рис. 2). Для меньших температур отжига имеется пик КРС от аморфной фазы германия $\left(\sim 275 \mathrm{~cm}^{-1}\right)[11,16]$, интенсивность которого находится в прямой зависимости от температуры отжига, что указывает на увеличение доли металлического германия. В отличие от случая наноструктур $\mathrm{Ge} / \mathrm{SiO}_{2}$ предельная температура отжига пленок $\mathrm{GeO}_{x}$ составляет $600^{\circ} \mathrm{C}[2,21]$, выше этой температуры они сублимируют. В нашем случае процесс сублимации протекает интенсивнее для пленок, сформированных на более горячих подложках, что иллюстрируется исчезновением полосы ИК-поглощения в области температуры отжига $600^{\circ} \mathrm{C}$ на рис. 4.

Здесь необходимо отдельно обсудить положение полос ИК-поглощения связей $\mathrm{Ge}-\mathrm{O}$, определяемое степенью нестехиометричности оксида германия $\mathrm{GeO}_{x}[11]$. 
В нашем случае (рис. 3 и 4) максимум поглощения колебаниями изгиба неотожженных пленок $\mathrm{GeO}_{x}$ лежит в области $785 \mathrm{~cm}^{-1}$ и смещается в область больших значений волнового числа с ростом температуры отжига. Это объясняется увеличением доли кислорода в $\mathrm{GeO}_{x}$, т.е. ростом $x$ от единицы к двум, сопровождаемым монотонным смещением и достижением максимумом поглощения значения $890 \mathrm{~cm}^{-1}$, типичного для стехиометрического диоксида германия.

Обобщая данные ИК-поглощения и КРС, можно заключить, что под действием отжига при температурах 400-600 ${ }^{\circ} \mathrm{C}$ в пленках $\mathrm{GeO}_{x}$ протекает процесс диссоциации на отдельные фазы $\mathrm{Ge}$ и $\mathrm{GeO}_{2}$, причем чем выше температура отжига, тем сильнее процесс. По-видимому, он идет по схеме $2 \mathrm{GeO} \rightarrow \mathrm{Ge}+\mathrm{GeO}_{2}$. Этот результат хорошо согласуется с данными по спектроскопии ближней тонкой структуры края рентгеновского поглощения отожженных пленок $\mathrm{GeO}_{x}$ из работы [22], где было показано, что распад $\mathrm{GeO}$ интенсифицируется в диапазоне температур отжига $260-480^{\circ} \mathrm{C}$, а средняя температура образования небольших нанокристаллов германия составляет $509^{\circ} \mathrm{C}$.

Следует также обсудить, как температура подложки влияет на состав и структуру пленок $\mathrm{GeO}_{x}$. Выше по отдельности были отмечены три особенности поведения пленок. Во-первых, доля металлического германия в пленках $\mathrm{GeO}_{x}$ по данным КРС (рис. 7) увеличивается с ростом температуры подложки вплоть до $300^{\circ} \mathrm{C}$. Во-вторых, в пленках с температурой формирования до $300^{\circ} \mathrm{C}$ наблюдается связываемая с HK Ge люминесценция в области $1.2 \mathrm{eV}$ (рис. 5), а свыше $300^{\circ} \mathrm{C}-$ свечение центров окраски в $\mathrm{GeO}$ при $1.6 \mathrm{eV}$. В-третьих, отжиг при температуре $600^{\circ} \mathrm{C}$ пленок $\mathrm{GeO}_{x}$, полученных при $220^{\circ} \mathrm{C}$ и выше, приводил к их сублимации: в спектрах КРС отсутствовали пики, связанные с металлической фазой германия (рис. 7,b, кривая 3), аналогично тому, как в ИК-спектрах не наблюдалось полос поглощения колебаний $\mathrm{Ge}-\mathrm{O}$ (рис. 3, $b$, кривая 3; рис. 4).

В качестве объяснения мы полагаем, что на более ,холодных“ подложках (до $\sim 300^{\circ} \mathrm{C}$ ) формировался гетерогенный композит из смеси фаз металлического германия, в частности нанокристаллов, и его субоксидов. Повышение температуры подложки, препятствуя формированию фазовых неоднородностей, стимулировало образование гомогенного $\mathrm{GeO}_{x-1}$. Подобные особенности фазового состава смеси германия и его оксидов отмечены в [21]. Разницу в поведении пленок при отжиге можно объяснить тем, что структуру пленок на „холодных“ подложках можно представить в виде смеси нерегулярных фазовых включений, образующих каркас, на разрушение которого требуется дополнительная энергия. Этим объясняется сравнительная устойчивость к сублимации при отжиге низкотемпературных пленок по сравнению с устойчивостью пленок, полученных при высоких температурах подложки.

\section{5. Заключение}

В работе получены структуры, содержащие нанокристаллы Ge в оксидной матрице, для которых экспериментально были обнаружены полосы люминесценции в области $1.2,1.5-1.7$ и $1.7-2.0 \mathrm{eV}$. Полоса фотолюминесценции с пиком при $1.2 \mathrm{eV}$ связана с изолированными германиевыми нанокристаллами с малой поверхностной плотностью. Световая эмиссия в более высокоэнергетической области $(1.6 \mathrm{eV})$ объясняется оптическими переходами центров окраски $\mathrm{GeO}_{x}$. Люминесценцию в диапазоне 1.7-2.0 eV мы связываем с конгломератами нанокристаллов германия, в излучении которых участвуют поверхностные дефекты границ НК $\mathrm{Ge} / \mathrm{SiO}_{2}$.

C технологической точки зрения сформированные структуры трудно назвать оптимальными, поскольку в наших условиях полученные пленки $\mathrm{GeO}_{x}$ сублимируют при температурах, меньших температуры кристаллизации германия, а отжиг многослойных нанопериодических структур $\mathrm{Ge} / \mathrm{SiO}_{2}$ ведет к формированию конгломератов дефектных нанокристаллов германия неправильной формы. Мы полагаем, что многослойная структура $\mathrm{GeO}_{x} / \mathrm{SiO}_{2}$ может позволить получить воспроизводимое формирование сферических малодефектных нанокристаллов германия.

Авторы выражают признательность Н.В. Байдусю за методическую помощь в измерении спектров фотолюминесценции.

\section{Список литературы}

[1] O.B. Gusev, A.V. Ershov, D.A. Grachev, B.A. Andreev, A.N. Yablonskiy. ЖЭТФ 145, 830 (2014).

[2] S. Kim, S.-W. Hwang, S.-H. Choi, R.G. Elliman, Y.-M. Kim, Y.-J. Kim. J. Appl. Phys. 105, 106112 (2009).

[3] M. Gallagher, U. Österberg. Appl. Phys. Lett. 63, 2987 (1993).

[4] Y. Maeda. Phys. Rev. B 51, 1658 (1995).

[5] A. Samavati, Z. Othaman, S.K. Ghoshal, S. Zare. Chin. Opt. Lett. 11, 112502 (2013).

[6] M. Zacharias, P.M. Fauchet. Appl. Phys. Lett. 71, 380 (1997).

[7] J.K. Shen, X.L. Wu, R.K. Yuan, N. Tang, J.P. Zou, Y.F. Mei, C. Tan, X.M. Bao, G.G. Siu. Appl. Phys. Lett. 77, 3134 (2000).

[8] S. Takeoka, M. Fujii, S. Hayashi, K. Yamamoto. Phys. Rev. B 58, 7921 (1998).

[9] T. Kanno, M. Fujii, H. Sugimoto, K. Imakita. J. Mater. Chem. C 2, 5644 (2014).

[10] А.В. Ершов, Д.А. Павлов, Д.А. Грачев, А.И. Бобров, И.А. Карабанова, И.А. Чугров, Д.И. Тетельбаум. ФТП 48, 44 (2014).

[11] M. Ardyanian, H. Rinnert, X. Devaux, M. Vergnat. Appl. Phys. Lett. 89, 011902 (2006).

[12] R. Peibst, J.S. de Sousa, K.R. Hofmann. Phys. Rev. B 82, 195415(2010).

[13] C.N. Ye, X.M. Bao, N.Y. Tang, L.J. Zhuge, W.G. Yao, J. Chen, Y.M. Dong, Y.H. Yu. Sci. Technol. Adv. Mater. 3, 257 (2002). 
[14] X.L. Wu, T. Gao, G.G. Siu, S. Tong, X.M. Bao. Appl. Phys. Lett. 74, 2420 (1999).

[15] A.V. Kolobov, A.A. Shklyaev, H. Oyanagi, P. Fons, S. Yamasaki, M. Ichikawa. Appl. Phys. Lett. 78, 2563 (2001).

[16] A.-M. Lepadatu, T. Stoica, I. Stavarache, V.S. Teodorescu, D. Buca, M.L. Ciurea. J. Nanopart. Res. 15, 1981 (2013).

[17] С.С. Горелик, Л.Н. Расторгуев, Ю.А. Скаков. Рентгенографический и электрооптический анализ: приложения. Металлургиздат, М. (1970). 366 с.

[18] M.J. Hytch. Microscopy Microanalys. Microstruct. 8, 41 (1997).

[19] E. Tuğay, S. Ilday, R. Turan, T.G. Finstad. J. Lumin. 155, 170 (2014).

[20] Y. Sasaki, C. Horie. Phys. Rev. B 47, 3811 (1993).

[21] И.В. Тананаев, М.Я. Шпирт. Химия германия. Химия, М. (1967). $452 \mathrm{c}$.

[22] C.J. Sahle, C. Sternemann, H. Conrad, A. Herdt, O.M. Feroughi, M. Tolan, A. Hohl, R. Wagner, D. LützenkirchenHecht, R. Frahm, A. Sakko, K. Hämälänen. Appl. Phys. Lett. 95, 021910 (2009). 